\title{
Insulin-like growth factor and growth hormone secretion in juvenile chronic arthritis
}

\author{
Roger C Allen, Mark Jimenez, Christopher T Cowell
}

\begin{abstract}
Insulin-like growth factor (IGF-1) concentrations were determined in a series of 23 children with juvenile chronic arthritis in conjunction with anthropometric assessment. When standardised $\mathrm{z}$ scores were used significant decreases in height and weight were shown in comparison with the normal age/sex matched means. Severe growth disturbance was seen, particularly in those with prolonged disease duration, which was independent of corticosteroid treatment, indicating disease activity itself is a major factor in the growth retardation. Eight children had low IGF-1 z scores-that is, less than $-\mathbf{2 . 0 0}$ from age/sex matched mean. Low IGF-1 $z$ scores were associated with low weight $\mathrm{z}$ scores but not with low -height $z$ scores. Overnight growth hormone secretory profiles were determined in 10 patients, including seven with low IGF1 , and showed generally normal secretion in all but one patient, who subsequently attained normal concentrations coincident with catch up growth. Increased pulse frequency of overnight secretion was commonly seen. Low IGF-1 concentrations probably result from varying factors, particularly nutritional, but do not reflect marked endocrinological abnormalities in most patients.
\end{abstract}

Poor somatic growth is a feature of juvenile chronic arthritis, particularly in the systemic and polyarticular onset forms of the disease. In Still's description ${ }^{1}$ 'arrest in development' was specifically noted, preceding by many years various therapeutic interventions, particularly use of corticosteroids, which have been implicated in contributing to the abnormal growth in juvenile chronic arthritis. ${ }^{2}$ Bernstein et al also showed that disease activity itself contributes to growth impairment. ${ }^{3}$

Normal growth is a complex interrelation of factors, including genetic, hormonal, and nutritional requirements. In the presence of normal thyroid function the secretion of pituitary growth hormone and the growth hormone dependent insulin-like growth factors (IGF), particularly IGF-1, form the predominant hormonal axis of postnatal growth. ${ }^{4}$ Normal growth hormone secretion has been shown in juvenile chronic arthritis by pharmacological stimulation ${ }^{5}$ or by secretory profiles of physiological secretion, ${ }^{6}$ yet, increased rate of growth has resulted from exogenous growth hormone treatment. ${ }^{7}$ Previous studies of IGF-1 concentrations in juvenile chronic arthritis have reported conflicting results-either reduced $^{89}$ or normal values, ${ }^{10}$ with or without correlation with corticosteroid treatment. ${ }^{89}$ Concomitant growth hormone secretion was not determined in any of these studies. Low IGF-1 secretion may occur in 'normal' short children, related to low growth hormone secretion rates, despite having normal responses to pharmacological stimulation with arginine/insulin or clonidine. ${ }^{11}$ In this study we monitored growth in relation to IGF-1 and physiological growth hormone secretion by 12 hour overnight sampling, in a group of patients with juvenile chronic arthritis, to investigate if an abnormality of the growth hormone/insulin-like growth factor axis, possibly related to altered sleep patterns, may be contributing to poor growth.

\section{Patients and methods}

Twenty three children (15 female, eight male) with juvenile chronic arthritis satisfying the EULAR classification criteria were studied. ${ }^{12}$ Disease onset subtypes were seven systemic, six polyarticular, and 10 pauciarticular. All children had continuing evidence of active disease as shown by the presence of synovitis in at least one joint requiring anti-inflammatory drug treatment. With the exception of one patient, referred specifically for the study from another hospital, all patients were attending the rheumatology clinic at the Children's Hospital, Sydney. Informed parental consent was given before entry to the study. All patients were over 4 years of age, the lowest age for which IGF-1 data were available. Mean disease duration was 3.2 years (range $0 \cdot 25-12$ ). At the time of entry into the study all patients were prepubertal except two (patients 1 and 5) who had attained Tanner stage 2 pubertal development, defined by the degree of pubic/axillary hair or breast development. All patients were taking nonsteroidal anti-inflammatory drugs. In addition nine were taking slow acting antirheumatic drugs and 10 were receiving oral corticosteroid treatment on alternate days.

Anthropometric measures included height, weight, mid-arm circumference, and skinfold thickness at four sites-subscapular, suprailiac, triceps, and biceps. Height, weight, and rate of growth were compared with age/sex matched United States National Center for Health Statistics growth standards. Weight for height for age ratios were graded by reported standards for nutritional sufficiency, the lower limit of normal being $90 \% .^{13}$ Indices for nutritional insufficiency were $85-90 \%$ (mild), $75-85 \%$ (moderate), $<75 \%$ (severe). Standardised deviation scores ( $\mathrm{z}$ score) for height and weight were \\ Department of \\ Camperdown, Sydney, \\ Department of \\ Endocrinology, \\ Australia \\ M Jimenez
}


calculated by reported methods ${ }^{14}$-namely, the difference between the patient's height (or weight) minus the age equivalent mean height (or weight), divided by the ideal height (or weight) standard deviation for age.

Insulin-like growth factor 1 was measured by a radioimmunoassay, ${ }^{15}$ from which a $\mathrm{z}$ score was calculated by the same method as height/weight $z$ scores using normal age and sex data. Seven of eight patients with an IGF-1 $\mathrm{z}$ score less than -2.00 underwent growth hormone studies. Three additional patients with poor rates of growth were also studied. Overnight sampling every 20 minutes was performed from 2200 to 0800 hours and analysed for the mean growth hormone secretion and the pulsatile pattern of secretion using the pulsar peak identification algorithm program (NICHD, Bethesda/University of California, Berkeley). ${ }^{16}$ Clonidine stimulation $(125 \mu \mathrm{g} / \mathrm{kg})$ of growth hormone secretion was performed in the initial six patients studied, but owing to a hypotensive episode in one patient this test was discontinued for the subsequent patients. A normal clonidine stimulation test was defined as a peak in growth hormone of $\geqslant 20 \mathrm{mU} / \mathrm{l}$. Growth hormone was measured by radioimmunoassay with second antibody separation using previously reported methods. ${ }^{17}$ Owing to wrist arthritis in many of the patients estimation of bone age was of limited value either because of destructive changes, precluding accurate assessment, or physial advancement of the affected carpus, presumed secondary to local hyperaemia.

The SPIDA statistical computer package (Statistical Laboratory, Macquarie University, Sydney) was used for the analysis, and the rejection level was set at $0 \cdot 05$. Comparison between groups was determined by the two sample $t$ test. Parameters of the secretory patterns were compared by linear regression analysis.

\section{Results}

ANTHROPOMETRIC MEASUREMENT

Table 1 shows the anthropometric findings. The mean (SD) height $\mathrm{z}$ score was -1.06 (1.24) and the mean weight $z$ score $-0.83(1 \cdot 14)$, which were both significantly reduced in comparison with age matched normal growth data (height $p=0.0005$, weight $p=0.002$ ). Patient number 6 had spent a number of years in a transit refugee camp before developing his arthritis and had probably experienced significant preceding nutritional impairment. When this patient was excluded significant differences in height and weight $\mathrm{z}$ scores remained between patients values and the normal growth data. Weight for height for age index was below $\mathbf{9 0 \%}$ in five cases, a level indicative of nutritional compromise. An additional six cases had $\mathrm{z}$ scores less than -1.5 for height or weight, or both, and yet had normal weight for height indexes owing to the proportional reduction in overall growth parameters. Skinfold and midarm circumference measurements gave no additional information about nutritional status than that given by the weight $\mathrm{z}$ score in this patient group (data not shown).

Significantly lower $\mathrm{z}$ scores were found in patients with prolonged disease duration $(>4$ years) for both height $(p=0.001)$ and weight $(p=0.027)$, but no correlation was found for either height or weight with corticosteroid treatment or disease onset subtype. Of note, however, three patients with pauciarticular onset (Nos 3, 17, and 21) had progressed to a polyarticular course, whereas those with persistent pauciarticular disease did not show such marked somatic disturbance.

\section{IGF-1/GROWTH HORMONE}

Eight patients (three systemic, two polyarticular, three pauciarticular) had IGF-1 z scores less

Table 1 z Scores for insulin like growth factor, height, and weight, for each patient with disease onset type, patient's age, and disease duration at the time of entry

\begin{tabular}{|c|c|c|c|c|c|c|c|c|}
\hline $\begin{array}{l}\text { Case } \\
\text { No }\end{array}$ & $\begin{array}{l}\text { Age } \\
\text { (years) }\end{array}$ & $\begin{array}{l}\text { Onset } \\
\text { type }\end{array}$ & $\begin{array}{l}\text { Disease } \\
\text { duration } \\
\text { (years) }\end{array}$ & Corticosteroids & $\begin{array}{l}I G F-I^{*} \\
(z)\end{array}$ & $\begin{array}{l}\text { Height } \\
(z)\end{array}$ & $\begin{array}{l}\text { Weight } \\
(z)\end{array}$ & $\begin{array}{l}\text { Weight/height } \\
\text { (\%) }\end{array}$ \\
\hline $\begin{array}{r}1 \\
2 \\
3 \\
4 \\
5 \\
6 \\
7 \\
8 \\
9 \\
10 \\
11 \\
12 \\
13 \\
14 \\
15 \\
16 \\
17 \\
18 \\
19 \\
20 \\
21 \\
22 \\
23\end{array}$ & $\begin{array}{r}10.8 \\
10.2 \\
8.7 \\
11.9 \\
14.6 \\
13.6 \\
12.6 \\
7.8 \\
6.3 \\
11 \cdot 0 \\
12.4 \\
5.5 \\
8 \cdot 1 \\
12.0 \\
8.9 \\
10.0 \\
9.0 \\
5.7 \\
7.3 \\
6.9 \\
4.5 \\
8.9 \\
6.3\end{array}$ & $\begin{array}{l}\mathbf{S}^{*} \\
\mathbf{P}^{*} \\
\mathbf{P a}^{*} \\
\mathbf{P} \\
\mathbf{S} \\
\mathbf{P a} \\
\mathbf{S} \\
\mathbf{P} \\
\mathbf{S} \\
\mathbf{S} \\
\mathbf{P a} \\
\mathbf{P} \\
\mathbf{P} \\
\mathbf{P} \\
\mathbf{P} \\
\mathbf{P} \\
\mathbf{P a} \\
\mathbf{P a} \\
\mathbf{P} \\
\mathbf{S} \\
\mathbf{P a} \\
\mathbf{P a} \\
\mathbf{P a} \\
\mathbf{P a}\end{array}$ & $\begin{array}{r}0.3 \\
4.0 \\
7.5 \\
0.6 \\
12.0 \\
0.6 \\
10.0 \\
1.6 \\
5.3 \\
4.1 \\
8.0 \\
2.0 \\
0.5 \\
0.9 \\
4.0 \\
0.6 \\
2.0 \\
3.0 \\
1.0 \\
0.3 \\
2.9 \\
3.0 \\
0.6\end{array}$ & $\begin{array}{l}+ \\
- \\
- \\
+ \\
- \\
+ \\
- \\
+ \\
+ \\
- \\
- \\
- \\
- \\
+ \\
- \\
- \\
+ \\
+ \\
- \\
+ \\
+ \\
-\end{array}$ & $\begin{array}{l}-3.02 \\
-2.59 \\
-2.65 \\
-3.02 \\
-3.45 \\
-3.78 \\
-3.12 \\
-1.27 \\
+1.61 \\
+1.89 \\
-2.10 \\
+0.32 \\
-0.11 \\
-1.91 \\
+0.23 \\
-0.32 \\
-0.96 \\
+2.00 \\
-0.46 \\
+1.71 \\
+0.95 \\
-0.37 \\
+1.12\end{array}$ & $\begin{array}{r}1.06 \\
-1.34 \\
-1.94 \\
-1.16 \\
-3.88 \\
-2.53 \\
-3.31 \\
-0.17 \\
-2.17 \\
-1.96 \\
-0.56 \\
0.63 \\
0.28 \\
-1.66 \\
-1.68 \\
-0.94 \\
-0.56 \\
-1.49 \\
-0.58 \\
0.00 \\
-0.57 \\
-0.05 \\
0.22\end{array}$ & $\begin{array}{r}0.48 \\
-1.51 \\
-3.15 \\
-1.04 \\
-2.21 \\
-2.64 \\
-2.45 \\
-1.17 \\
-0.65 \\
-0.29 \\
-0.77 \\
-0.04 \\
1.11 \\
-1.42 \\
-1.22 \\
0.56 \\
-0.87 \\
-0.86 \\
0.76 \\
0.05 \\
-1.83 \\
-0.03 \\
0.08\end{array}$ & $\begin{array}{r}99 \\
89 \\
62 \\
98 \\
124 \\
88 \\
104 \\
85 \\
99 \\
125 \\
96 \\
91 \\
115 \\
97 \\
94 \\
116 \\
90 \\
91 \\
113 \\
93 \\
73 \\
102 \\
91\end{array}$ \\
\hline $\begin{array}{l}\text { Mean } \\
\text { SD }\end{array}$ & & & & & $\begin{array}{r}-0.84 \\
1.89\end{array}$ & $\begin{array}{r}-1 \cdot 06 \\
1 \cdot 24\end{array}$ & $\begin{array}{r}-0.83 \\
1 \cdot 14\end{array}$ & \\
\hline
\end{tabular}

*S=systemic; $\mathrm{P}=$ polyarticular; $\mathrm{Pa}=$ pauciarticular; $\mathrm{IGF}-1$ =insulin like growth factor 1 
Table 2 Mean growth hormone secretion (MGHS) and description of pulsatile physiological growth hormone secretion by number of peaks, peak amplitude, and mean length of peaks for patients undergoing overnight study

\begin{tabular}{|c|c|c|c|c|c|}
\hline \multirow{3}{*}{$\begin{array}{l}\text { Case } \\
\text { No }\end{array}$} & \multirow{3}{*}{$\underset{(m U / l)}{M G H S}$} & \multicolumn{4}{|l|}{ Peaks } \\
\hline & & \multirow[t]{2}{*}{ Number } & \multicolumn{2}{|c|}{ Amplitude (mU/l) } & \multirow{2}{*}{$\underset{(\min )}{\text { Mean length }}$} \\
\hline & & & Maximum & Mean & \\
\hline $\begin{array}{l}1(\mathbf{a})^{*} \\
\text { (b) } \\
2 \\
3 \\
4 \\
5 \\
6 \\
7 \\
8 \\
9 \\
10\end{array}$ & $\begin{array}{r}2.35 \\
14.12 \\
4 \cdot 01 \\
4.49 \\
4.77 \\
5.25 \\
8.02 \\
5.17 \\
8.75 \\
7 \cdot 22 \\
5.02\end{array}$ & $\begin{array}{l}6 \\
5 \\
3 \\
6 \\
6 \\
6 \\
7 \\
4 \\
4 \\
7 \\
7\end{array}$ & $\begin{array}{l}11.5 \\
76.9 \\
31.3 \\
27.9 \\
21.2 \\
25.7 \\
39.1 \\
25.6 \\
39.6 \\
50.7 \\
23.1\end{array}$ & $\begin{array}{r}6.7 \\
27.9 \\
16.0 \\
13.0 \\
9.7 \\
13.4 \\
19.4 \\
19.3 \\
18.1 \\
21.0 \\
11.8\end{array}$ & $\begin{array}{r}53 \\
108 \\
67 \\
60 \\
57 \\
77 \\
51 \\
100 \\
105 \\
60 \\
51\end{array}$ \\
\hline
\end{tabular}

*Patient 1 was studied on two occasions about 12 months apart.

Patients 1-7 had an insulin-like growth factor (IGF) $\mathrm{z}$ score less than $-2 \cdot 00$, whereas patients 8-10 Pat an IGF $\mathrm{z}$ score greater than $-2 \cdot 00$.

than $-2 \cdot 00$ from the age/sex matched mean. Only three of the patients with low IGF-1 were receiving corticosteroid treatment. As a corollary, seven further patients receiving corticosteroid treatment had IGF-1 $\mathrm{z}$ scores between -0.46 and 2.00 .

Seven of the eight patients with low IGF-1 and three additional patients (Nos 8, 9, and 10) who showed poor rate of growth underwent overnight growth hormone estimation (table 2). In comparison with previously published data from our laboratory, the overall mean growth hormone secretion of the patients with juvenile chronic arthritis $(5.5 \mathrm{mU} / \mathrm{l})$ was greater than that of children with growth hormone deficiency $(1.5 \mathrm{mU} / \mathrm{l})$ and that of short statured children with normal growth hormone response to pharmacological stimulation $(4.6 \mathrm{mU} / \mathrm{l}){ }^{18}$ Seven of the 10 patients studied, however, had mean growth hormone secretion within the range of the growth hormone deficient group $(0.39-5.5 \mathrm{mU} / \mathrm{l})$. The mean number of pulses, $5 \cdot 5$ (range 3-7), was greater than previously seen in our growth clinic (unpublished observation). All six patients with juvenile chronic arthritis studied had normal response to clonidine stimulation. Patient 1 , who before the onset of systemic onset juvenile chronic arthritis was growing on the 97th centile, improved in rate of growth, IGF-1 concentration, and mean growth hormone secretion as her disease state went into remission, with catch up growth being seen (figs 1 and 2). She continued to receive steroids throughout this time. Pubertal development also occurred, reflected in increased oestradiol from 44 to $181 \mathrm{pmol} / 1$ over this period. Overall, the IGF $\mathrm{z}$ scores correlated with both the height and weight $\mathrm{z}$ scores (IGF $v$ height $r=0.43, p=0.042$; IGF $v$ weight $r=0.46$, $p=0.028$ ). The mean weight $z$ score of those patients with an IGF-1 $\mathrm{z}$ score less than -2.00 was significantly less than those greater than $-2.00(-1.79$ compared with $0.41, p=0.007)$. The height $\mathrm{z}$ scores, however, failed to reach a significant difference $(-1.87$ compared with $-0.70, p=0.065$ ). No significant association was shown between IGF-1 and rate of growth or between mean growth hormone secretion and rate of growth or height/weight $\mathrm{z}$ scores (data not shown). The mean growth hormone secretion correlated with the amplitude of the secretory peaks, both maximum $(r=0.94, p<0.001)$

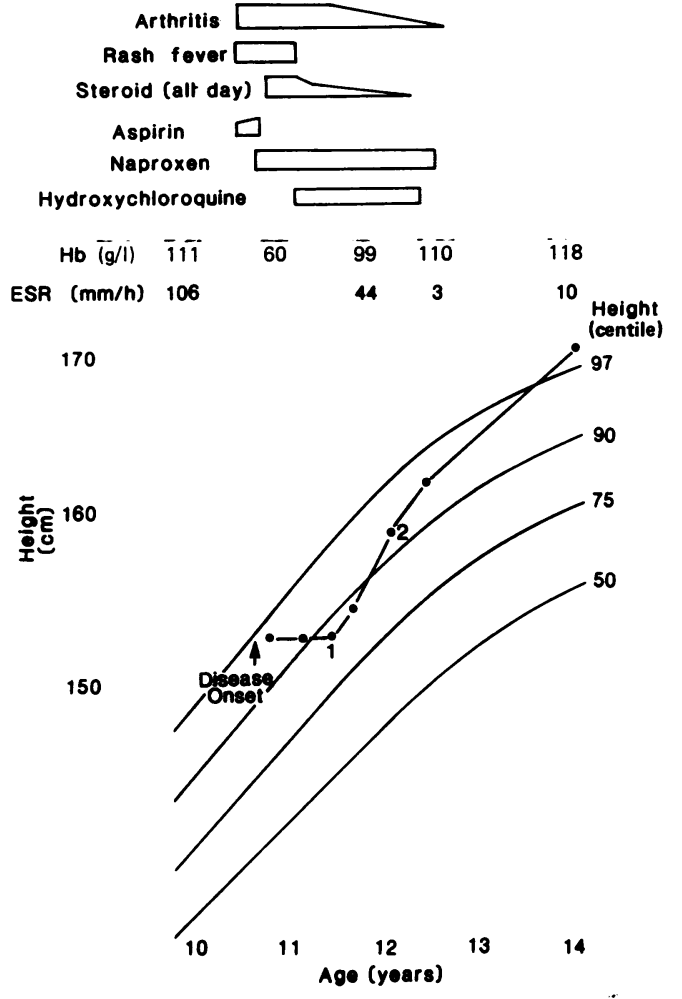

Figure 1 Disease course of girl with systemic onset juvenile chronic arthritis showing interruption to linear growth during the active disease period. Points 1 and 2 represent the times of insulin-like growth factor/mean growth hormone secretion estimations.

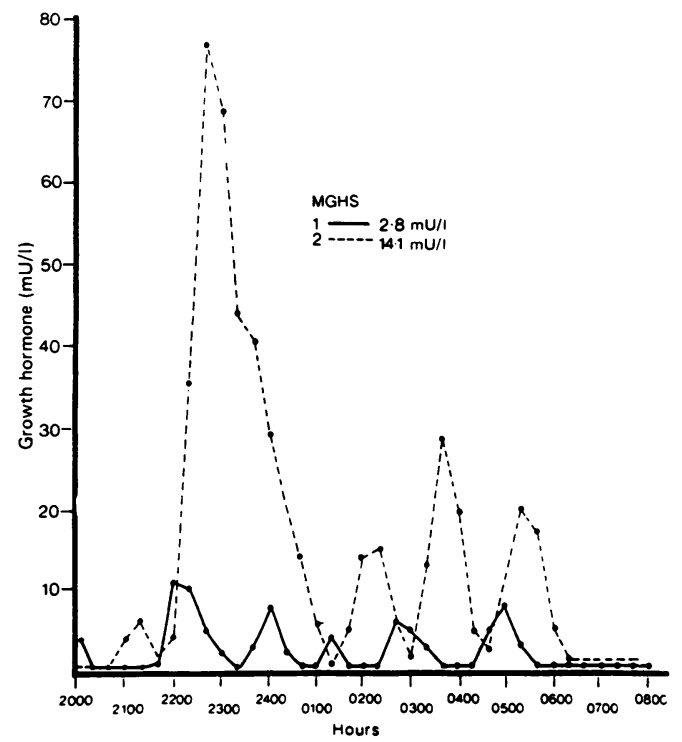

Figure 2 Growth hormone secretory profile. Solid line is secretion when disease was most active and dashed line is secretion as disease entered remission, at time points 1 and 2 in fig $1 . M G H S=$ mean growth hormone secretion.

and mean ( $r=0.87, p<0.001)$, and with the length of the peaks $(r=0.62, p<0.05)$. No correlation was found between the IGF-1 $z$ score and mean growth hormone secretion $(\mathrm{r}=0 \cdot 34, \mathrm{p}=0 \cdot 32)$.

\section{Discussion}

Growth disturbance in juvenile chronic arthritis is of considerable importance as it may be a persisting legacy of the disease after the active inflammatory process has apparently abated. 
Considerable concern has evolved about the limitation of linear growth secondary to corticosteroid treatment, somewhat overshadowing the potential effect of the disease process itself. With the recognition of growth hormone secretion and subsequent IGF-1 production as the predominant hormonal stimulus to growth, studies have investigated possible abnormalities in this axis in a variety of chronic disease states-for example, Crohn's disease, ${ }^{15}$ chronic renal failure, ${ }^{19}$ thalassaemia major ${ }^{20}$-though no consistent abnormality has been shown.

Growth hormone secretion has been stimulated by drugs, but no abnormality has been shown in juvenile chronic arthritis irrespective of the corticosteroid regimen used-daily, alternate day, etc. ${ }^{21}$ This was confirmed in our study with those children receiving treatment on alternate days. Butenandt, however, showed improvement in rate of growth in patients with juvenile chronic arthritis during exogenous growth hormone treatment. ${ }^{7}$ Growth hormone is secreted in a pulsatile nature, especially during sleep; abnormalities in this physiological pattern of secretion, particularly in the amplitude of the pulses, are reported in short children who have responded normally to insulin/arginine provocation of growth hormone secretion. ${ }^{11}$ Furthermore, low IGF-1 concentrations are also reported in such children. As low IGF-1 concentrations have been noted in systemic onset juvenile chronic arthritis ${ }^{8}$ this study aimed at determining physiological growth hormone patterns in children with low IGF-1, the hypothesis being that poor sleeping patterns due to disease may be blunting the physiological response.

We confirmed that IGF-1 may be low in patients with all disease onset subtypes and not only in those with systemic onset. No consistent growth hormone secretory abnormality was shown, however, though some patients did have low concentrations, falling within the range of growth hormone deficient patients. The increased pulse frequency that we noted may reflect disturbances of hypothalamic control of growth hormone secretion either because of abnormal sleep patterns or poor nutrition. Our sample size limited further analysis of the interaction between nutrition and growth hormone secretion. Variability of physiological growth hormone secretion with overlap between normal and growth hormone deficient children has been described. ${ }^{22}$ Furthermore, variability between consecutive periods of sampling ${ }^{23}$ shows the possible limitations in the investigation of physiological secretion. Chipman et al also studied physiological secretion in patients with polyarticular juvenile chronic arthritis, concluding that no abnormality was present as all patients had at least one peak exceeding 10 $\mathrm{ng} / \mathrm{ml}$ during sleep. ${ }^{6}$ Considerable variability of 24 hour growth hormone secretion was also shown as in our study.

One patient was found to have a dramatic improvement in rate of growth concomitant with increases in both IGF-1 and mean growth hormone secretion. Although pubertal development was a likely contributor, as confirmed biochemically, the improvement coincided with disease remission, and rate of growth seemed more exaggerated than would be expected for puberty alone. This suggests that catch up growth, in disease remission, may have an endocrinological component in some cases.

Previous reports have used reduction in weight for height for age index to indicate nutritional impairment, ${ }^{24} 25$ whereas we also used weight $\mathrm{z}$ scores to indicate possible nutritional compromise. This may be more meaningful than calculating the index alone as the index does not detect patients with proportional reduction of both height and weight. Low IGF-1 and normal/raised growth hormone concentrations are found in malnutrition, ${ }^{26}$ which, as suggested by Bennett et al, ${ }^{8}$ may be occurring in patients with juvenile chronic arthritis. Insulinlike growth factor 1 was in closer association with weight $\mathrm{z}$ score than height $\mathrm{z}$ score, further reflecting a possible link with nutritional status. The weight $\mathrm{z}$ score was not reduced in patient 1 , who showed catch up growth associated with increases in both IGF-1 and mean growth hormone secretion. Studies of a potentially treatable situation, such as poor nutrition, are the basis for further study.

This study does not exclude the possibility that exogenous growth hormone treatment may be of benefit in individual patients with persistently poor rate of growth, but such an approach should only be considered after careful consideration of nutritional factors and maximum control of the disease process.

We thank Dr Robert Baxter for performing the IGF-1 measurements, Drs Macauley, Tyndall and Champion for referral of patients, and Mrs Pat Findlay and Carol Dunn for assisting with the manuscript.

1 Still G F. On a form of chronic joint disease in children. Med Chir Trans 1897; 80: 47. (Reprinted Arch Dis Child 1941; 16: 156-65.)

2 Ansell B M, Bywaters E G L. Alternate-day corticosteroid therapy in juvenile chronic polyarthritis. $\mathcal{F}$ R heumatol 1974; 1. $176-86$.

3 Bernstein B H, Stobie D, Singsen B H. Growth retardation in juvenile theumatoid arthritis. Arthritis Rhewm 1977; 20: 212-6.

4 Bercu B B, Diamond Jr F B. A determinant of stature: regulation of growth hormone secretion. Adv Pediatr 1986; 33: 331-80.

5 Butenandt $\mathrm{O}$, Kelch A, Rajmann E. Growth hormone studies in patients with rheumatoid arthritis with or without glucocorticosteroid therapy. Eur $\mathcal{f}$ Pediatr 1974; 118: 53-62.

6 Chipman J J, Boyar R M, Fink C W. Anterior-pituitary adrenal function of gold-treated patients with juvenile adrenal function of gold-treated patients with

7 Butenandt $O$. Rheumatoid arthritis and growth retardation in children: treatment with human growth hormone. Eur $\mathcal{J}$ Pediatr 1979; 130: 15-28.

8 Bennett A E, Silverman E D, Miller III J J, Hintz R L. Insulin-like growth factors I and II in children with systemic onset juvenile arthritis. $\mathcal{f}$ Rheumatol 1988; 15: $655-8$.

9 Aitman T J, Palmer R G, Loftus J, et al. Serum IGF-1 levels and growth failure in juvenile chronic arthritis. Clin Exp Rhewounal 1989; 7: 557-61.

10 Takami M, Taguchi T, Nagashima K. Endocrinological studies on growth retardation in children with juvenile rheumatoid arthritis. Ryumachi 1982; 22: 19.

11 Spiliotis B E, August G P, Hung W, Sonis W, Mendelson W, Bercu B B. Growth hormone neurosecretory dysfunction. Bercu B B. Growth hormone neurosecretory dysfunction.
A treatable cause of short stature. FAMA 1984; 251: A treatable cause of short stature. FAMA 1984; 251: 2223-30.

12 Ansell B M. Chronic arthritis in childhood. Ann Rheum Dis 1978; 37: 107-20.

13 McLaren D S. Nutritional assessment. In: McLaren D S, Burman D, eds. Textbook of paediatric nutrition. 2nd ed. Edinburgh: Churchill Livingstone, 1982: 88-99.

14 Dibley M J, Staehling N, Nieburg M P H, Trowbridge F L. Interpretation of $\mathbf{Z}$-score anthropometric indicators derived from the international growth reference. Am $7 \mathrm{Clin} N u$ 1987; 46: 749-62.

15 Kirschner B S, Sutton M M. Somatomedin-C levels in growth-impaired children and adolescents with chronic inflammatory bowel disease. Gastroenterology 1986; 91: 830-6. 
16 Merriam G R, Wachter $\mathrm{K}$ W. Algorithms for the study of episodic hormone secretion. Am f Physiol 1982; 243: E310-8.

17 Kirk I A, Raghupathy P, Stevens M M, et al. Growth failure and growth hormone deficiency after treatment for acute and growth hormone deficiency after treatment

18 Cowell C Greenacre P, Jimenez M, Quigley C, Howard N, Silink M. Circadian and statural attenuation of growth hormone pulse amplitude and duration. Proceedings of the hormone pulse amplitude and duration.

19 Spencer E M, Uthne K O, Amold W C. Growth impairment with elevated somatomedin levels in children with chronic renal insufficiency. Acta Endocrinol (Copenh) 1979; 91: 36-48.

20 Werther G A, Matthews R, Burger H G, Herington A C. Deficiency of non-suppressible insulin-like actin thalassaemia maior. Arch Dis Child 1981 . 56: 855-9.

21 Sturge R A, Beardwell C, Hartog M, Wright D, Ansell B M. Cortisol and growth hormone secretion in relation to linear growth: patients with Still's disease on different therapeutic regimes. BMF 1970;

22 Lin T H, Kirland R T, Sherman B M, Kirkland I L. Growth hormone testing in short children and their response to growth hormone. F Pediat 1989; 115: 57-63.

23 Donaldson D L, Hollowell J G, Pan F, Gifford R A, Moore $W V$. Growth hormone secretory profiles: variation on consecutive nights. 7 Pediatr 1989; 115: $51-6$.

24 Lovell D J, Gregg D, Heubi J, Levinson J E. Nutritional status in juvenile rheumatoid arthritis (JRA)_an interim report. Proceedings of a Conference on Rhewomatic Diseases of Childhood. Park City, Utah, 1986.

25 Bacon M C, White P H. A new approach to the assessment of growth in JRA [Abstract]. Arthritis Rhewon 1987; 30 (suppl): 192.

26 Hintz R L, Suskind R, Amatayakul K, Thanangkul O, Olson R. Plasma somatomedin and growth hormone values in children with protein calorie malnutrition. $\mathcal{P}$ Pediatr 1978; 92: 153-6. 